\title{
Part of the Tribe: Event Crews, Residence, and Affiliation in Underground Dance Music Scenes
}

\author{
Christopher Charles \\ University of Bristol \\ cc12642@bristol.ac.uk
}

\begin{abstract}
With diverse roots including the Jamaican sound system, the New York hip-hop collectives, and the UK rave crews of the early 1990s, the event ' $\mathrm{Crew}^{\prime}$ ' is an important organising force in contemporary electronic dance music cultures. These small groups of individuals are responsible for bringing together performers, audience, equipment, and venue. This is rarely profitable and in fact tends to incur losses - most crewmembers willingly put in their time and effort for free. This work is vital to the maintenance of local EDM scenes; however, it has often gone unnoticed by scholars and the media. Drawing on my recent research into psychedelic trance (psytrance) culture in Bristol, UK, this paper details the activities of three urban event crews in a thriving local scene. It then looks at the concepts of 'residence' and 'affiliation' which denote formal or quasi-formal relationships between artists, crews, and record labels. Throughout, the paper aims to illuminate the role that these relationships play in musical careers and the structure of music scenes more widely.
\end{abstract}

KeYWORDS: Promotion; Psytrance; Crews; Residence; Affiliation; EDM

\section{Introduction}

Event organisation has been neglected by scholars of music until recently. Promoters, the individuals and small groups who organise music events, "have hitherto been academically neglected (and often publicly maligned) individuals and organisations" (Webster 2011:9), viewed as part of the corporate machinery of the music industry and more often associated with profit than artistic endeavour. The crucial work that they do in supporting musical communities has been underappreciated, and the many promoters who do not make money from music events, or even willingly make losses in the support of a music scene, have gone largely unnoticed. 
This article seeks to address the issue by looking at a particular kind of social grouping that emerges around music event organisation: the $\operatorname{EDM}(1)$ event crew (henceforth ' $c r e w$ '), a handful of individuals who work together to put on an electronic dance music event. This crew is responsible for finding a venue, booking artists, providing equipment, and making sure that an event runs smoothly. Independent crews of this kind are particularly associated with underground dance music or "UDM" cultures (Fikentscher 2000), although they can also be found in commercial dance music scenes. They carry a connotation of DIY music-making and countercultural values stemming from their cultural roots, which will be explored shortly.

EDM crews are distinct from other kinds of music event promoters in a number of ways. Firstly, they are not usually venue owners nor hired by a venue; neither are they attached to a particular artist, record label, or booking agency. Rather, they are independent units able to move from location to location and create a shifting pattern of relationships with venues and artists of their choosing. They may be understood as curators who draw together various elements - venue, artists, sound equipment, and decorations - and present them to an appreciative audience. This is not always profitable and in fact tends to incur financial losses. As such, their motivations for undertaking such work are deserving of further study.

This article draws on my research into psychedelic trance (psytrance) culture in the city of Bristol conducted between 2014 and 2018 (Charles 2019). During this time I interviewed scene members, attended events, kept a field diary, and eventually learned to perform psytrance and related musics as a DJ. This brought me into contact with a number of crews, each occupying a niche in the local musical ecosystem. Some were large, others small; some put on regular events, others held only one event and then disbanded. However, each contributed in its own way to the psytrance scene in Bristol and the UK more widely. Their work was also vital in providing an income for performing musicians, especially given the falling monetary value of musical recordings. The activity of these crews therefore has much to reveal about the nature of musical careers and musical communities in the $21^{\text {st }}$ century.

\section{Previous Writing on Event Crews}

As noted earlier, event organisers and promoters have only recently become a focus of attention in scholarly writing. This is a subject suited to ethnographers operating within an 'art worlds' (Becker 1982) or 'scenes' (Straw 1991) framework, especially where grassroots or underground music-making is concerned. Finnegan's (2007) 1989 study of amateur musicians in Milton Keynes is perhaps the first to acknowledge the work done by non-musicians in sustaining local music event cultures. This work has been crucial in bringing the 'art worlds' perspective to bear on urban music-making, directing attention to the people who contribute to musicmaking and their motivations for doing so. The subsequent music scenes literature has substantially broadened how musical participation is understood and helped scholars move from a consumption-oriented subcultural model towards a more inclusive approach integrating various forms of cultural production (Bennett 2004). The motivations and careers of event promoters, however, have remained relatively unexamined.

Emma Webster (2011) has offered the first extended ethnographic study of this topic. Looking at individuals and groups putting on events in Sheffield, Bristol, and Glasgow (UK), she finds promoters to be "cultural investors (and exploiters), 
importers and innovators who both shape and are shaped by the live music ecology within which they operate" (10). Observing the centrality of live music in contemporary music careers and the role of the promoter in bringing together musicians and audience, Webster notes that promoters are "both local cultural champions and cultural importers; they both promote local artists and bring nonlocal artists from around the UK and from around the world into a locality" (128). Typologies are given for varieties of music promoter, event types, and means of generating publicity, substantially expanding our vocabulary for event organisation. However, specific categories and concepts deployed within particular music scenes (such as 'crew' and 'sound system') are absent.

The ethnographic literature on EDM itself, although generally inclusive in terms of looking at a broad range of participation activities, has rarely looked at event organisation specifically, instead focusing on audiences, musicians, and venues. Where event promoters or crews appear, it is usually in the context of a wider phenomenon or project, such as the Nortec collective detailed by Madrid (2008) or Petiau's (2012) writing on free parties in French teknival culture. Studies of careers and musicianship in EDM (Reitsamer 2011; Farrugia 2012) have likewise highlighted the social aspects of event organisation but haven't directly addressed the crew itself as a mode of musical sociality. The formal and quasi-formal relationships which emerge between crews, record labels, and individual performers have yet to receive substantial ethnographic treatment.

Details on historic EDM crews can be found in histories of dance music and DJoriented cultures, notably those by Reynolds (2013) and Brewster and Broughton (2007). These are narrative accounts focusing on noted figures and famous events in dance music history, and they lack detail on the more prosaic aspects of event organisation. Nonetheless, they help us to trace the development of the modern UDM crew and to identify some important predecessors in other DJ-oriented musical cultures. The most important among these is arguably the Jamaican sound system (Brewster \& Broughton 2007: 116-131; Henriques 2010). Emerging in the 1950s-1960s, this consisted of a mobile group of musicians and sound engineers playing ska, rocksteady, and reggae music in competitive events. To this end, they would collect or construct powerful sound equipment and commission exclusive tracks from local musicians and producers. The sale of tickets and drinks created an income for sound system members and a means of improving their equipment and record collection. The sound system thus constituted a "sociotechnical ensemble" (Henriques 2010: 32) with human, material, and conceptual components.

A second crucial forerunner was the hip-hop collective, which emerged in The Bronx, New York, in the late 1970s (Brewster \& Broughton 2007; Vernon 2018). Here, DJs would work alongside MCs, sound engineers, and dancers (b-boys or bgirls) to put on neighbourhood events. Again, there was a competitive element with rival DJs engaging in music and breaking battles - the term 'crew' emerged in this context as a means of denoting "groups of individuals who decide, formally, to make their affiliation with each other known" (Fogarty Woehrel 2019: 121). Later, as hip-hop became a commercially successful music genre, 'crew' began to connote something closer to a band, namely a network of rappers and producers working together musically. The concept thus became part of a wider musicalcultural vocabulary, bringing implications of loyalty and rivalry, cooperation and dispute.

Electronic dance music emerged in the U.S. in the early 1980s, shortly after hiphop (Brewster \& Broughton 2007: 290-371; Butler, 2006; Reynolds 2013). This culture was initially oriented around particular venues with charismatic owners and 
high-profile resident DJs. As such, independent event crews were not a formative aspect of the culture. However, as EDM travelled across the Atlantic to the UK, it took on a more itinerant form. Sound system culture had arrived with the post-war influx of Jamaican migrants, and Brits were familiar with its central concepts powerful sound equipment, informal word-of-mouth parties, and exclusive or rare records. Following this model, UK rave crews began putting on events in fields and warehouses around the country. These were highly successful for a while and some crews were able to make substantial amounts of money from the sale of tickets and drinks (Reynolds 2013). Others put on 'free parties' funded by donations, a continuation of "the UK's rich tradition of free festivals and countercultural gatherings" (O'Grady 2015: 77). This activity was stifled by the Criminal Justice and Public Order Act (1994) which gave police the power to shut down large gatherings with loud music. However, independent crews continued to operate in the UK, putting on smaller raves and free parties in secret locations. This is no longer a profitable activity - rather, participants seem to be motivated by "the excitement of being part of Britain's cultural underground" (Rosca 2014).

Today's urban UDM crews draw from a rich cultural heritage which includes several DJ-oriented music scenes from across the world. Like the Jamaican sound system, New York hip-hop crew, and UK rave crew, they are highly mobile, often owning their own equipment and bringing it from location to location. They are independent from venues and performers - in Webster's (2011) typology they are "independent" (2011: 38) promoters - although they may have DJs among their ranks. They are entrepreneurial and self-motivated, although this does not necessarily translate into financial gain. Most importantly, crews enable a wide range of musical participation strategies, from performing to dancing, decorating, and sound-engineering. They focus a music scene's creativity and perform the vital function of bringing together its various elements in a particular space and time.

\section{Organising a Psytrance Party}

The following sections of this paper look specifically at psytrance culture (psyculture), a branch of EDM culture with a strong international scene. Unlike house, techno, or jungle, psytrance did not originate in a Western urban centre, but rather within a diasporic community of hippies living on the beaches of Goa, India (D'Andrea 2007; Saldanha 2007; St. John 2010, 2012). It has subsequently developed along similar lines to other EDM cultures and shares many of their organisational properties. It is relatively self-contained, however, and has a few unique characteristics - namely an emphasis on intricate and colourful decorations, an elaborate genre system tied to the day/night cycle, and close integration of a wider hippie culture focusing on crafts and physical performance activities (handmade clothes, vegan/vegetarian food, juggling or fire performance). The psytrance crew is therefore typical of UDM crews more widely, although psytrance events have some idiosyncratic features which must also be taken into consideration.

The first crews in the original Goa scene were small groups of performers working together to put on monthly full-moon parties. To do so they had to negotiate with the local police, procure necessary equipment, and set up in a remote location (often a beach or wooded area) with little in the way of access by road. These individuals were often performers themselves, and their motivations were not necessarily financial: 
An average trance party required a budget of about Rs. 35,000 (US\$750). Western party promoters raised the money, which was equally spent on renting the sound system and on bribing (baksheesh) police officers. (...) By all means, promoters were glad to break even; if not, they paid any difference with their own resources. They were aficionados who organized parties because they wanted to play and be acknowledged as scene DJs. A team of party promoters involved a small group of friends. Veteran freaks operated in more international networks, whereas younger promoters grouped themselves by nationality (usually Israelis). Each team sought to promote one, seldom two parties each season, or face the risk of party saturation. (D'Andrea 2007: 197)

Ideally, such parties would last all night and well into the next day. At first, the music was progressive and psychedelic rock; later, it became a blend of electronic beats, Indian classical music, and film scores. The consumption of psychoactive substances added an otherworldly dimension and gave structure to the proceedings: an average acid trip, for example, is around twelve hours long, with a peak of intensity at around six hours, necessitating a longer event with a strong musical structure.

This party format and the associated musical repertory spread throughout the world in the early 1990s. Notable scenes emerged in Israel, South Africa, Australia, Japan, Brazil, and Europe. The music evolved into Goa trance and then psytrance, and from there into a spectrum of closely-related genres with colourful names: 'fullon', 'morning', 'forest', 'psybient'. The night-long parties gradually became two- or three-day events and extra stages were added for different kinds of music. In addition, new ways of participating in psyculture became prevalent, including physical performance (dance, juggling), visual arts (painting, decorating), and selling handmade items (clothing, jewellery).

Alongside these large outdoor events, urban club nights also play an important role in psyculture, although they have been somewhat neglected by scholars and other writers addressing the psytrance scene. In Europe, club nights are somewhat specific to the colder months: dedicated fans will travel to festivals throughout the summer and return home to attend nightclub events during the autumn and winter. These might be seen as translocal and local manifestations of psyculture respectively. However, the point at which the local ends and translocal begins is unclear. Participants understand psyculture as a global phenomenon, a worldwide family or 'tribe' with localised branches gathering around particular events. St. John (2012) describes these local groups as "psytribes", noting that participants "adopt the 'tribal' identifier as an expression of their desire to be together" (7). More widely, these are connected by shared membership and the fact that psytrance musicians and fans travel extensively, attending events and mingling with other groups across the world. Urban event crews are a subset of these wider groupings - they are 'part of the tribe' - who perform the function of bringing together psytrance fans and artists outside of the festival season.

Organising a psytrance party in a nightclub is a laborious process. First, a venue must be found. This must be relatively affordable to hire; the owners must be willing to stay open late and to accommodate particular requests or uses of venue space, such as art galleries, massage tables, chai stalls, juggling or dancing, which are not typical of other club cultures. Staff and security must be willing to put up with attendees acting strangely and willing to resolve issues without immediately throwing people out or calling the police, as this is highly traumatic for participants undergoing a psychedelic experience. (Ideally, the community itself should deal with these issues, as would be the case at a free party or rave where there is no 
external security.) These criteria significantly narrow the number of venues which can be used.

Second, the line-up must be organised. If an event runs from 10p.m. until 7a.m. and has two stages, then between eight and twelve acts must be booked, each playing a one to two-hour slot. Some artists may need to be flown in from abroad and put into accommodation; others will be more local and require less assistance. Crew members will often collect performers from an airport or train station, sometimes whilst the event is occurring - this is a source of considerable stress as late flights or missed connections may cause an artist to miss their slot. Some of this work may be delegated to resident performers, non-crew participants, or even other crews: the 'takeover' is a common occurrence in which a smaller crew organises a particular stage or portion of a larger event's line-up.

Third, the technological requirements of the event must be met. A high-quality sound system must be acquired. If the in-house equipment is insufficient then equipment may be brought into the venue and operated by external professionals, adding considerably to the cost of the event. Certain brands are particularly wellknown (such as Funktion-One and Void Acoustics in the UK) and the name may appear on promotional material as a form of advertising. In addition, the promoters will need to provide a mixer and decks for the performers, as well as power and cables for connecting these together. Generators may be needed for additional power; if the event is well-attended then electric fans will be needed to circulate air. These smaller pieces of equipment may be the property of individual crew members or sourced from the wider network of friends and helpers.

Psytrance parties are also visually spectacular, necessitating considerable investment in decorations. For indoor and night-time events, as much of the venue as possible is lit with UV light and every surface covered in fluorescent decorations. The audience also wears UV-reactive clothing and makeup to create a maelstrom of bright colours in the darkness. Projections and lasers are used, contributing to the otherworldly atmosphere. Psytrance crews therefore spend huge amounts of time and money decorating a venue before use. Some build up a stock of decorations which are used from event to event; others hire external décor crews who bring their own items and equipment. Separate UV cannons and other lighting may also be required. It can take days to put up the decorations for a psytrance party and days to take it all back down again.

An extraordinary amount of time and effort therefore goes into organising a psytrance event. This is performed not only by the crew, but by a wide network of other individuals, including artists, vendors, other crews, and regular attendees. The majority of this work is unremunerated: many participants get involved simply for the opportunity to attend the event. Artists, too, will often play for free. This creates an interesting dynamic when it comes to professional musicianship: performers tend to have a strong notion of their monetary value and their relationship with music-making as a work or leisure activity. Smaller local artists may waive their performance fees if an event has failed to make money, for example, allowing travelling artists to be paid and the crew to stay out of debt.

Besides crews, other social groupings play an important role in connecting musicians and audience within the psytrance scene. Record labels are perhaps the most important example. Like event organisation, running a label is a curatorial activity in which various items (tracks, artwork, mastering engineer, distribution channel, video) are gathered, assembled, and presented to the wider scene. The difference between event crew and label is not always clear: crews may release and promote music, whereas labels may organise and promote events. Some groups 
actively blur this line altogether. The crew and the label, although similar, are thus important structuring principles in UDM careers and underground scenes more widely. They may be understood as participation strategies with attendant risks and rewards for members: involvement may lead to a more fulfilling career in a music scene, although at the expense of considerable time and effort, and often money.

\section{Psytrance Events in Bristol}

The following sections detail three crews, which were operating in Bristol during my study from 2014 to 2018 (Charles 2019). Extracts are given from a series of semi-structured interviews with crewmembers and performers. These interviews covered a range of topics and were not necessarily focused on event organisation; nonetheless, they convey the numerous challenges which promoters face in bringing their ideas to fruition. The events in question varied in terms of size, genre profile, and crew structure, but were otherwise united by their status as club nights rather than festivals or free parties, and may be seen as typical of urban psytrance events more widely.

\section{Tribe of Frog}

Tribe of Frog is the biggest and most famous psytrance event in Bristol, and one of the largest in the UK. It takes place monthly in a large venue called Lakota throughout the autumn, winter, and spring. In the summer, Tribe of Frog has an outdoor Summer Gathering and puts on stages at UK festivals such as NozStock and BoomTown. This yearly cycle is the centre around which the rest of the Bristol psytrance calendar is organised, and which other crews must take into account in order to avoid a clash of interests. The night is attended by students and ordinary Bristol residents as well as dedicated psytrance fans, resulting in a mixed crowd with varying levels of commitment to psytrance culture.

The Tribe of Frog crew formed in London in the 1990s as a décor crew called Wild Frogs. As such, they were not responsible for booking musicians or advertising events. The crew changed their name and began putting on their own parties when they relocated to Bristol in 2000. However, decorations remained a central component of their events, and they continued to design and build new pieces. Today, Tribe of Frog is largely organised by one person, Jason Frog, who has a background in graphic design. (Crew members are often referred to in this fashion, with the crew name appended to their first name.) Jason hires the venue, books the musicians, and does much of the decorating himself. However, the other crew members help in various ways, for example by selling tickets at the door, providing equipment, and so on.

The monthly events in Lakota attract around a thousand audience members. The venue has four stages spread over three floors which play music continually from $10 \mathrm{pm}$ until 7am, around thirty-six hours of music in total. The musical content of these varies from month to month: the first stage always plays full-on and progressive psytrance, which are the 'mainstream' genres of psytrance (Lindop 2010); the second stage tends to be oriented towards techno but may play other genres such as house or electro-swing; the third stage plays dark, forest, and hi-tech - the faster, more niche variants of psytrance (St. John 2011; Vitos 2009); the fourth stage plays a range of more relaxed genres, from psychedelic dub to glitch, liquid drum ' $n$ ' bass, and Goa trance. Organising this amount of music every month is an 
enormous undertaking. For this reason, each stage has one or more resident DJs who play regularly and who may also help Jason with the lineup.

Tribe of Frog is a visually spectacular event. Almost every surface in the venue is covered in fluorescent artwork, most of which is hand-painted (Figure 1). These decorations are all owned by the crew, and no external artwork is needed. It takes Jason five days to put these up and a further three to take them down again. Events are themed in a yearly cycle: for example March is always 'Frogz in Space' with futuristic decorations, and there is always a Hallowe'en event in October with monsters and ghouls. Attendees are invited to dress accordingly. These decorations are an important aspect of Tribe of Frog's visual branding and appear frequently in promotional material.

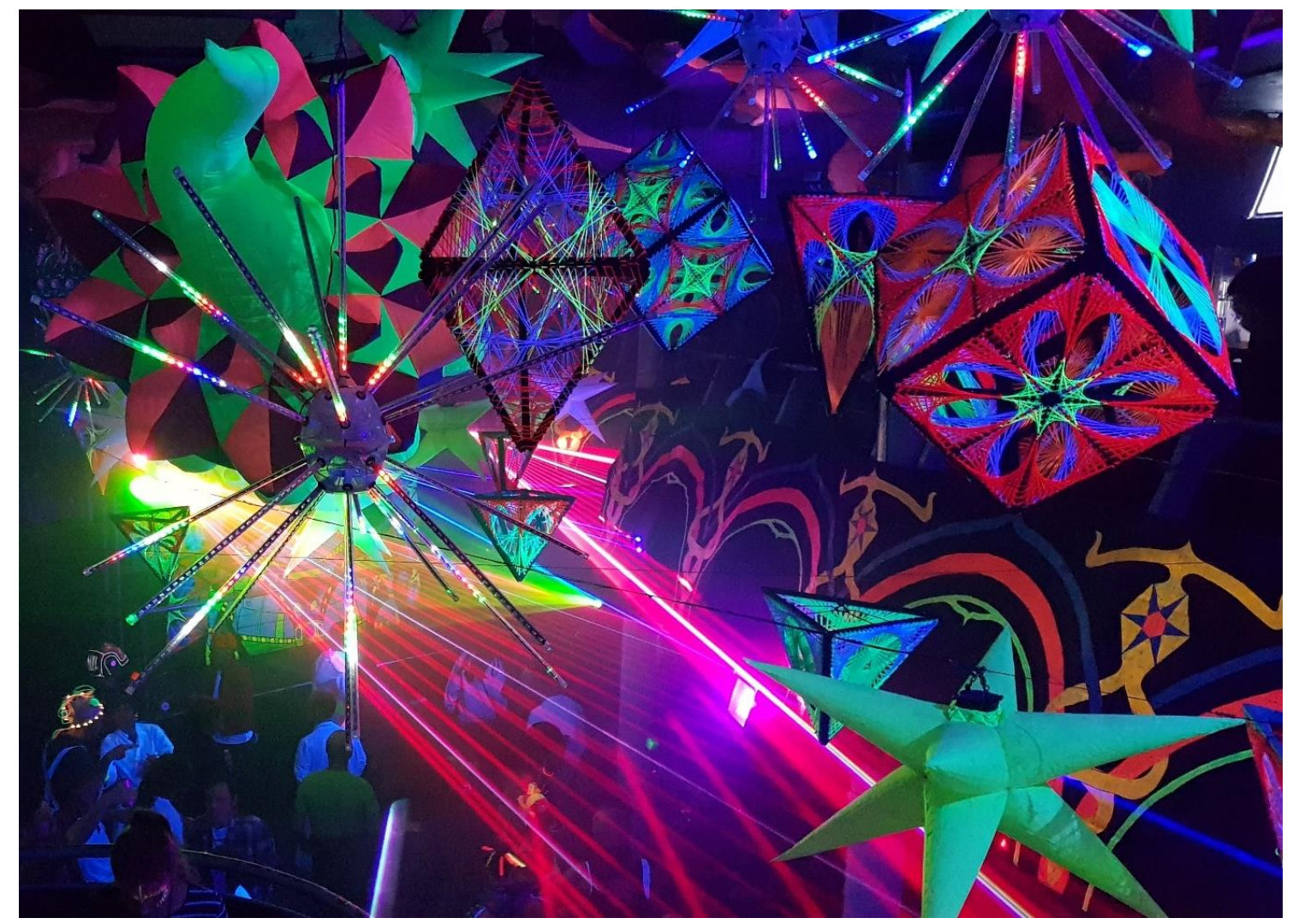

FIGURE 1. The main room at Tribe of Frog, March 2019.

Tribe of Frog's success is due in part to its strong relationship with its host venue Lakota, which is owned by a Bristol family with a long history in venue ownership. Over the years, the crew have helped to improve the venue: installing fans, widening doorways, or providing electricity to remote corners. In return, they have been granted storage space on the premises for decorations and equipment. It has thus been advantageous for the crew to establish this long-term relationship, which allows both the event and the venue to flourish.

For Jason, Tribe of Frog is a full-time job and his main source of income. When he is not preparing the venue, he is booking artists, advertising the event across multiple internet platforms, creating new decorations, and maintaining the website. In the week leading up to a Tribe of Frog event he is at the venue almost constantly. Jason makes a modest living from these activities despite long hours of work. Nonetheless, Tribe of Frog demonstrates that UDM promotion can be a full-time occupation for some participants. 


\section{Planet Shroom}

After Tribe of Frog, Planet Shroom is Bristol's second largest psytrance event. The crew is an amalgamation of two previous crews, Planet Easton and Shroom, which merged in 2005. Today it has two main members: Lurk, who books the artists, and Sean Shift (also known as Illumashroom) who finances the event and performs a laser show. Both are also DJs who perform at the events. However, there is a wider network of friends, previous crewmembers, and local psytrance fans who also help out. The event is held three or four times a year in the Trinity Centre, a large churchturned-music venue situated near Bristol city centre, and draws a crowd of 300-400 people.

Unlike Tribe of Frog, Planet Shroom has only one stage which exclusively plays psytrance music. As such, it is a night for dedicated psytrance fans. Lurk normally plays at the beginning, and Sean at the end; some well-known international producers and DJs play in between. The crew do not have many decorations of their own and will normally hire an external crew to provide them, notably the UKbased décor crew InOrbit. These pieces may consist of stretches (large sheets of Spandex stretched and punctured to make curvy, organic shapes), string art (fluorescent string nailed to wooden frames in intricate patterns), or more conventional wall hangings and mobiles. Illumashroom's laser show is performed live using a laptop and controllers, adding motion to the event's lighting (Figure 2).

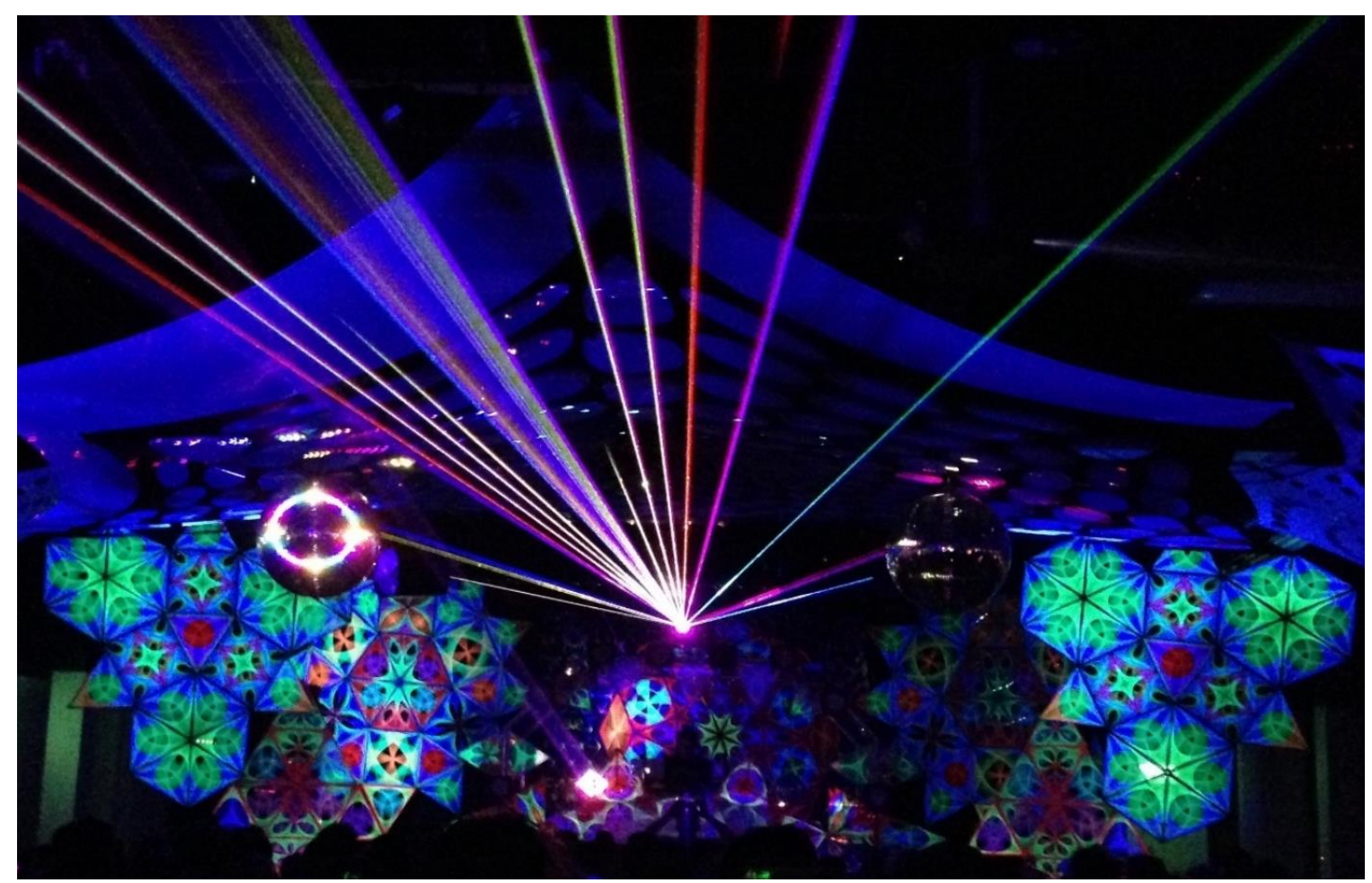

FIGURE 2. Lasers and string art at Planet Shroom, February 2015.

As a smaller, more niche event, Planet Shroom must place itself carefully within the wider live music ecosystem in Bristol. This is challenging and the costs of failure are considerable: 
C: So what's the hardest thing about putting on a night? What's the big thing that you think 'people don't realise how tricky this is'?

L: It's just the amount of other stuff that you're competing with. And not just within the music scene, it's like, you know... There's so much stuff in people's lives competing with everything else and it's just making yourself heard, finding a voice, getting in (...). And the stress of losing money. I mean, Sean has lost four-figure sums doing it before.

C: Whoa!

L: And, since I've been involved, and you think you've nailed it, you think you've got it, and something happens and someone puts on a party in Devon. One of our October parties (...), it was nice weather and someone decided to put on an outdoor party in Devon.

C: Last minute?

L: At the last minute. For a party like Shroom that ordinarily only gets three hundred people in, and probably needs a few more than that to break even, it took probably fifty people away.

C: Yeah.

$\mathrm{L}$ : Which is five hundred quid, and that's the biggest stress about it. I find myself watching the door like a hawk for the first two or three hours (...) trying to work out if we got more people in than usual at that stage.

(Lurk 2015)

As stated above, Sean finances the event and absorbs any losses, so that the continuation of the night is not threatened by poor attendance. This is one of many instances where a promoter willingly puts time and money into maintaining a local event - without this contribution, performers, decorators, and venue staff would not get paid. It is therefore clear that Planet Shroom operates not for profit, nor to boost their performing careers, but rather for the joy of bringing together the local psytrance audience:

L: It's so rewarding, you know? I find it's more rewarding than DJing for me, especially when it all goes off and you give everyone a night that they really, really enjoy (...). And my favourite bit about doing Shroom is that our crowd comes early, stays late.

C: *Laughs* They do, they really do. I do.

L: And watching the lights go on at the end, halfway through Sean's last track

- you don't get that anywhere else, you know (...) It's a ritual I've been seeing for twenty years and it never fails to satisfy me or make me feel proud that we've done something, you know, to put a bit of colour in people's lives.

(Lurk 2015)

\section{Psychedelic Jelly}

Psychedelic Jelly (or Psy Jelly) is a night dedicated to psychedelic downtempo music, meaning slower non-trance genres such as psybient, psydub, and psybreaks (Lindop 2010). This is unusual, as such music is usually confined to the second rooms and side stages at larger psytrance events. The event thus fills a very particular niche in the psychedelic music spectrum. Its emergence in 2017 caused excitement among local fans and performers of these genres, who are not necessarily interested in psytrance itself but attend psytrance events for the music presented on the alternative stages. Bristol, with its history of innovation in dub 
reggae, jungle/drum \& bass, and trip-hop (Henning \& Hyder 2015; Webb 2004) was seen as a fitting place to start a new downtempo scene.

The Psy Jelly crew began as a group of friends who had met on a juggling course in Bristol. The idea of putting on an event occurred after a summer of travelling, when they were all looking for jobs and living at the house of crewmember Fractal Forest:

They were living here for a couple of months, I think, and we were all really into downtempo psychedelic music, so we'd be playing each other what songs we'd found and stuff. And we were like, 'Aw, dammit, I wish there was a night where we could go and dance to this sort of music', you know? And it was like, yeah, why don't we do it? (Fractal Forest 2018)

Forest became the event's main organizer and resident DJ; the four other housemates helped through creating decorations, financial contribution, and general networking. In addition, two more resident DJs were drafted from the pool of downtempo performers in Bristol, including myself as 'Geoglyph'. I thus had a privileged view of the night's inception and development.

The biggest initial challenge for Psy Jelly was finding a suitable venue. Independent venues in Bristol were dwindling in number and the ones that remained were expensive. The Trinity Centre, for example, cost around $£ 900$ plus VAT to hire in 2017. After some searching, the first event was held in a volunteerrun theatre and art space called the Jam Jar. This was frequented by young, creative volunteers who understood the nature of psychedelic culture and were amenable to the quirks of such events. However, it was a small venue, and there were issues with licensing and noise complaints from the neighbours. As such, it could not act as a long-term home for the Psy Jelly.

After trying other venues, the crew eventually settled on the Jack of Diamonds, a former strip club which had recently come under new management. Seated areas, private booths, and a stage evidenced its previous function; these were found suitable for relaxing and juggling, which are normal activities at a downtempo event. Furthermore, the new owners were keen to attract a regular customer and offered venue alterations and considerable booking privileges. Fractal Forest was enthusiastic about this arrangement:

Yeah, that's like our new home I think now. I'm happy with it. Like, it's not huge, but I quite like the room. Like, being friends with the carpenter there was really useful. He basically put up these two bits of wood on the front wall and back wall just for us, because we wanted to hand up some décor, because then we could string stuff above. So they're really useful - not many venues would be like, 'Yeah, I just nailed a bit of wood into my wall for you'. (Fractal Forest 2018)

In addition to their nights at the Jack of Diamonds, Psy Jelly have also begun to collaborate with local psytrance nights and small festivals, contributing a second downtempo stage to nights otherwise focused on psytrance. A 'jellyfish' theme has been established and the crew has crafted and acquired several original decorations to this effect (Figure 3). As such they are able to bring performers and distinctive decorations with them to other events. 


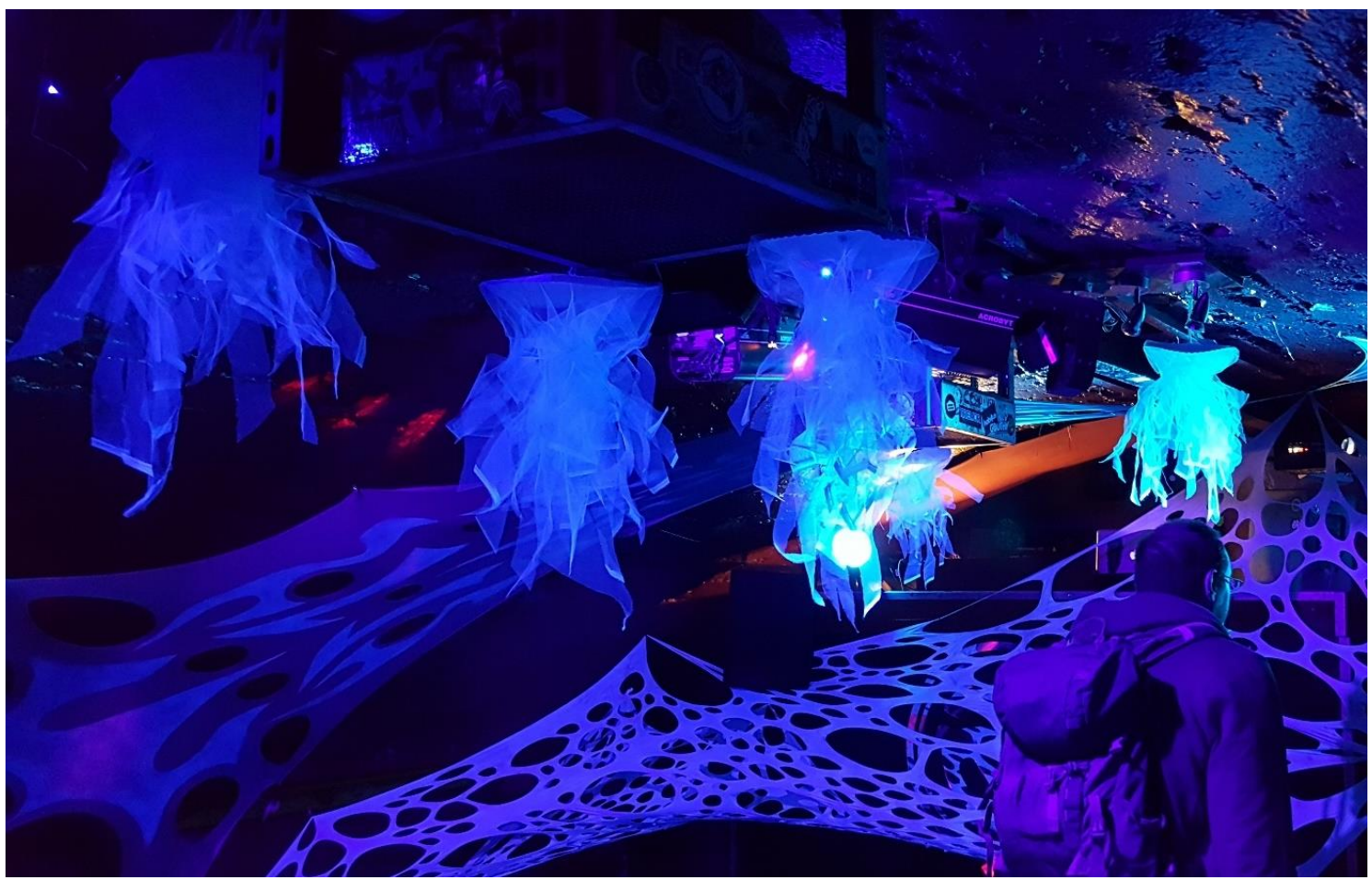

FIGURE 3. Jellyfish decorations at Psy Jelly, November 2017.

Psy Jelly have also released several albums and compilations online, making them a good example of an event crew turned record label. Fractal Forest acts as the label manager, taking responsibility for contacting artists, organising mastering and artwork, and managing the label's BandCamp page and social media presence. Other crewmembers and various friends are involved in diverse ways, for example as musicians, graphic artists, or mastering engineers. Furthermore, although the label is primarily focused on Bristol artists, some compilations have featured producers from outside the city. As such, this activity widens the social network of the crew considerably and strengthens ties between Bristol and the wider psychedelic scene.

\section{Residence and Affiliation}

In UDM cultures 'residence' commonly refers to a relationship between a DJ and a crew, although in other historic cultures and contexts it has referred to a relationship between DJ and a venue (Brewster \& Broughton 2007; Reynolds 2013). The performer may or may not be considered a crew member and will have varying degrees of responsibility for organizing an event. Their job is to perform regularly, to represent the aesthetics of the crew, and to warm up the dancefloor for headlining acts. As such, residents do not normally perform at 'peak' hours (1-3am) but rather in the early or late stages of an evening. Tetrasound, a psytrance DJ and one of the participants in my Bristol study, described his experience of becoming a resident at a night called Toadstool:

T: That was super cool. I mean, partying with those people a really, really long time, I was visiting them all the time, and then I played - they asked me to play once, and again and again, and I started playing more and more. And then 
[two of the crew members] asked me if I want to become a resident. So yes, so then I was on every single lineup playing with them, and that was pretty cool. C: So what does a resident have to do? What does a resident do?

T: Resident... I think just warming the dancefloor on the highest possible level. And there's no 'what a resident must do' but promote the night, get involved in the party itself. Personally, I didn't really help much with decorations. I was in Bristol but there were other people doing this. I should have a little bit more, but I haven't done it, so there's no excuse really. [Laughs] (Tetrasound 2016)

All of the nights mentioned in the previous section have residents. Some of these are central crewmembers who perform at their own events (such as Lurk and Fractal Forest) whilst others are more peripheral. Their specific duties vary: the residents at Tribe of Frog often help out with organising the line-up, for example, whereas the Psy Jelly residents had few responsibilities except to turn up and play when.

Attaining resident status is a significant milestone in the career of a DJ. It is a mark of aesthetic and technical ability, as well as a source of income and exposure. For residents joining a crew from the outside this is often a gradual process of befriending the crew and demonstrating reliability as a performer. Krosis is a producer and DJ who is one of the residents at Tribe of Frog, specialising in the fast, abstract style known as 'dark psytrance':

C: So tell me about becoming a resident?

$\mathrm{K}$ : I remember Jason just asked me one day. I hadn't even considered it before then tbh, but I think I was playing Tribe pretty regularly beforehand, and even giving the odd booking suggestion(...) [A previous resident] had also left as his career had blown up, so there was a vacancy for a younger darker dj.

(...)

C: What were your new responsibilities?

K: Not much really, just play as many parties as possible, but if I had another booking, Jason was always happy for me to take that if I let him know before flyers went off.

(Krosis 2019)

Like Tetrasound, Krosis began as an attendee, secured a few performing slots, and was later offered residence in recognition of his continuing musical progression and dedication to the event. Gradually, he has accrued more responsibilities including organising the lineup for Room 3 (the dark psytrance room). He also helps with the Tribe of Frog stage at Boomtown, and has established his own crew, Hitechnicians, to cater for very fast psytrance styles. His work at Tribe of Frog has thus led to further opportunities for involvement in psytrance events in the UK - as noted here, Tribe of Frog are happy to let him take other bookings when needed.

Residence may be contrasted with 'affiliation', which normally refers to a relationship between a DJ and a record label. Here, the performer represents the label at events by playing the label's music or music with a similar aesthetic. (Producers may also be referred to as 'affiliates' of a record label, although this relationship has different expectations in performance - notably that producers will play their own music.) For a DJ, affiliation with a noteworthy label may lead to more prestigious bookings; in return, the label is exposed to a wider audience. Tetrasound explains the duties of a label DJ: 


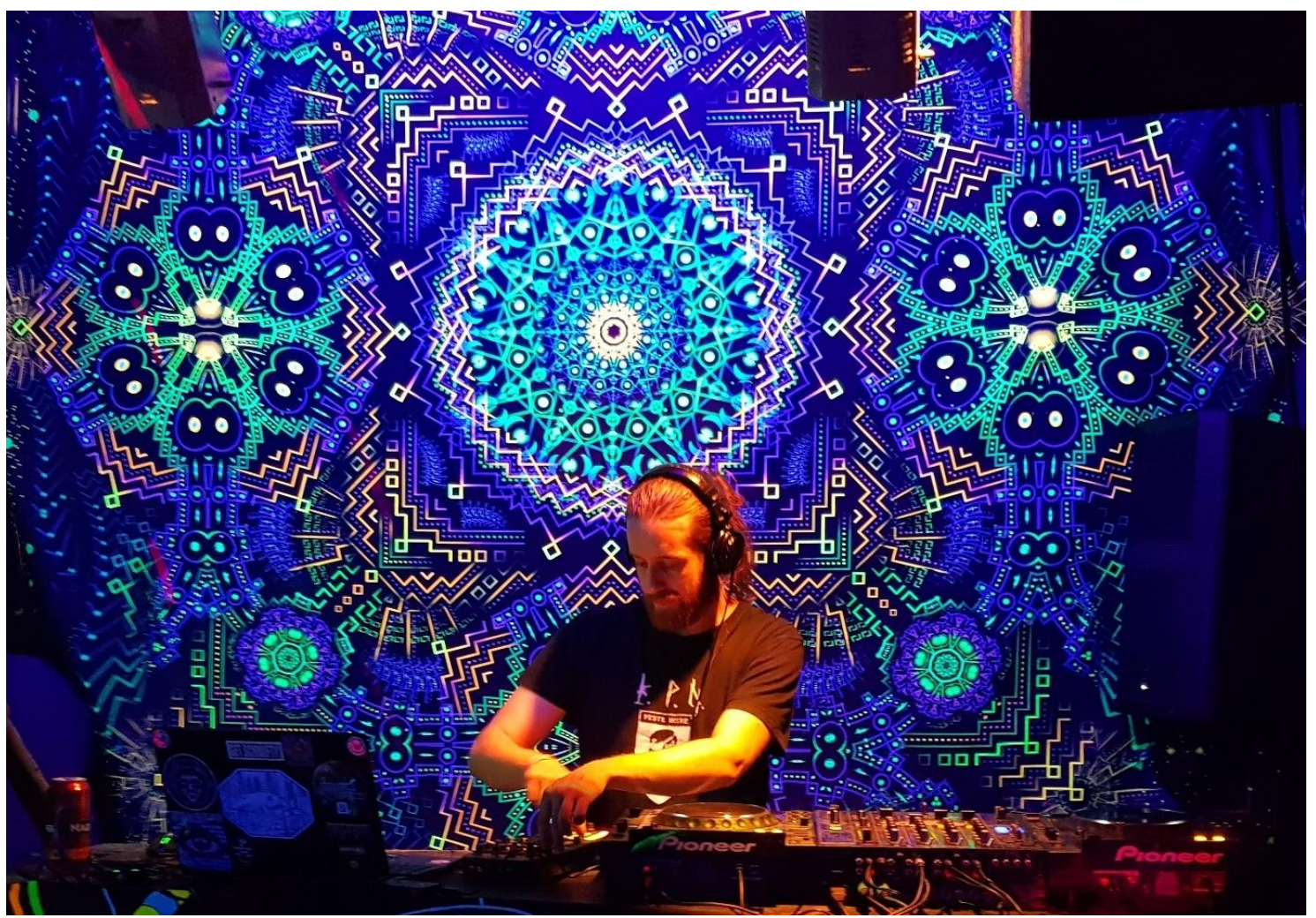

FIGURE 4. Krosis performing at Tribe of Frog, April 2019.

Most of it is promoting the music, and also it's good if the DJ could promote the parties as well... organise parties. So all the friends from the crew, all the people from the record label, artists who write music, they're also able to play. So you promote them, you promote the name of that record label, and, yeah, it's all the promotion and getting more gigs, more bookings, and to promote the music so people are buying more CDs and the message is spreading around. (Tetrasound 2016)

As noted previously, record labels often organise events of their own. Here, label members - including affiliated DJs - operate much like a crew, working together to procure a venue, equipment, artists, and an audience. The aim is to celebrate the label's organisational and aesthetic capabilities, and its pulling power within the psytrance scene.

A good example of this occurred in Bristol on December 14th 2014 . The event was organised by the labels Blacklite and Maharetta and took place in the Black Swan, an underground music venue in Easton. Tetrasound (Blacklite) and another local DJ, Neutron (Maharetta), were responsible for organising the venue, artists, and decorations, which were provided by external décor crews 2Deko and Ink Junkie. As seen in Figure 5, the performers on psytrance stage were members of the labels that organised the event; however the performers on the 'chillout' stage were not, but rather artists from the UK downtempo scene. This stage reflected the wider tastes of the label members rather than the sound of the labels themselves, which specialise in psytrance music. The event lost around 1000, but this was not considered too disappointing: it had performed its function of advertising and celebrating the participating labels. 
BLACKLITE RECORDS E MAHARETTA RECORDS PRESENT

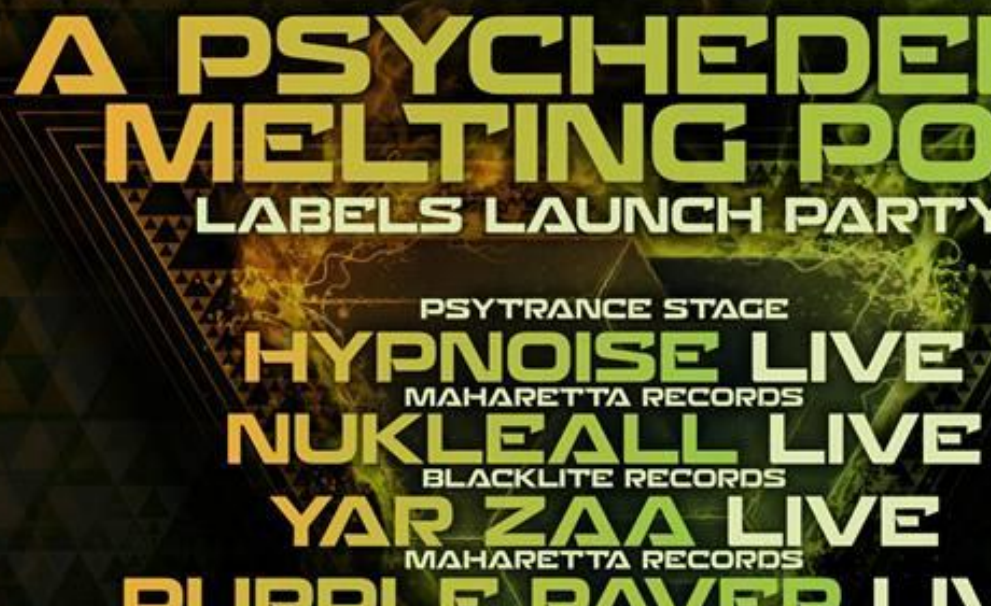

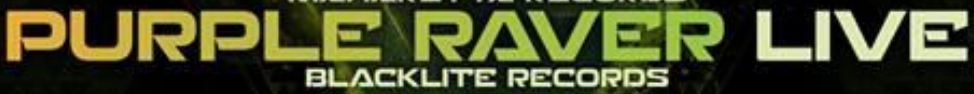

N 1 IIAHARETTARECORDS

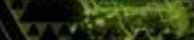
CHILLOUT STACE

EADE E

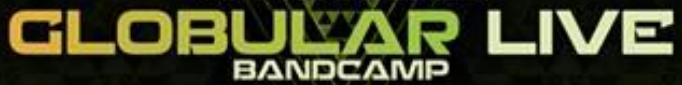
RAMA OOOP PHANTASM RECORDS

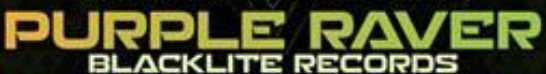

TECHHICAL THOUCHTS DACHSHUND RECORDS

DECO: ZDEKO (EGODROP), INK JUNKIE LICHTS: SION $\square$ SUUND BY TIMECATE

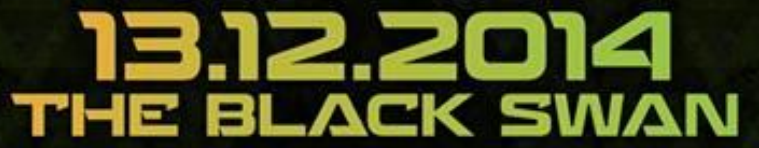

4ヨ日 STAPLETON ROAD, BRISTOL BSS GNR D ZZ:00-G:00

EARLY BIRDS: E9+BF D E-TICKETS: EID+BF D DOQR: EIZ E-TICKETS: www.etickets.to/buy/?e=12024

FIGURE 5. The flyer for 'A Psychedelic Melting Pot', December 2014.

A performer may have more than one residency or affiliation. Krosis, for example, is a resident DJ at Tribe of Frog, but also a producer who releases his own music. At first, he was associated with a Bristol label called Woo Dog records; later he was signed by a prestigious label from Italy called Blue Hour Sounds. However, his previous relationships did not come to an end: 
Woo Dog are chuffed that I got on Blue Hour, because Woo Dog have had so many other artists go from Woo Dog to other big labels. (...) But it doesn't mean we stop our association with them, and because I'm still a Tribe resident and doing other DJ sets as Krosis, I'm always going to have a DJ live role as well as a live set live role. (Krosis 2017)

As noted here, these associations overlap and interact in complex ways: as a producer, Krosis is expected to play his own music in a 'live set' format - that is, with some parts performed live using digital instruments (Butler 2014) - but as a resident/affiliated $D$ J he has an obligation to present a wider musical variety in performance. More widely, the live set is not compatible with residency, as the performer would be playing the same music at each event. Krosis must therefore balance these two aspects of his musical career, sometimes appearing as a live act and sometimes as a DJ.

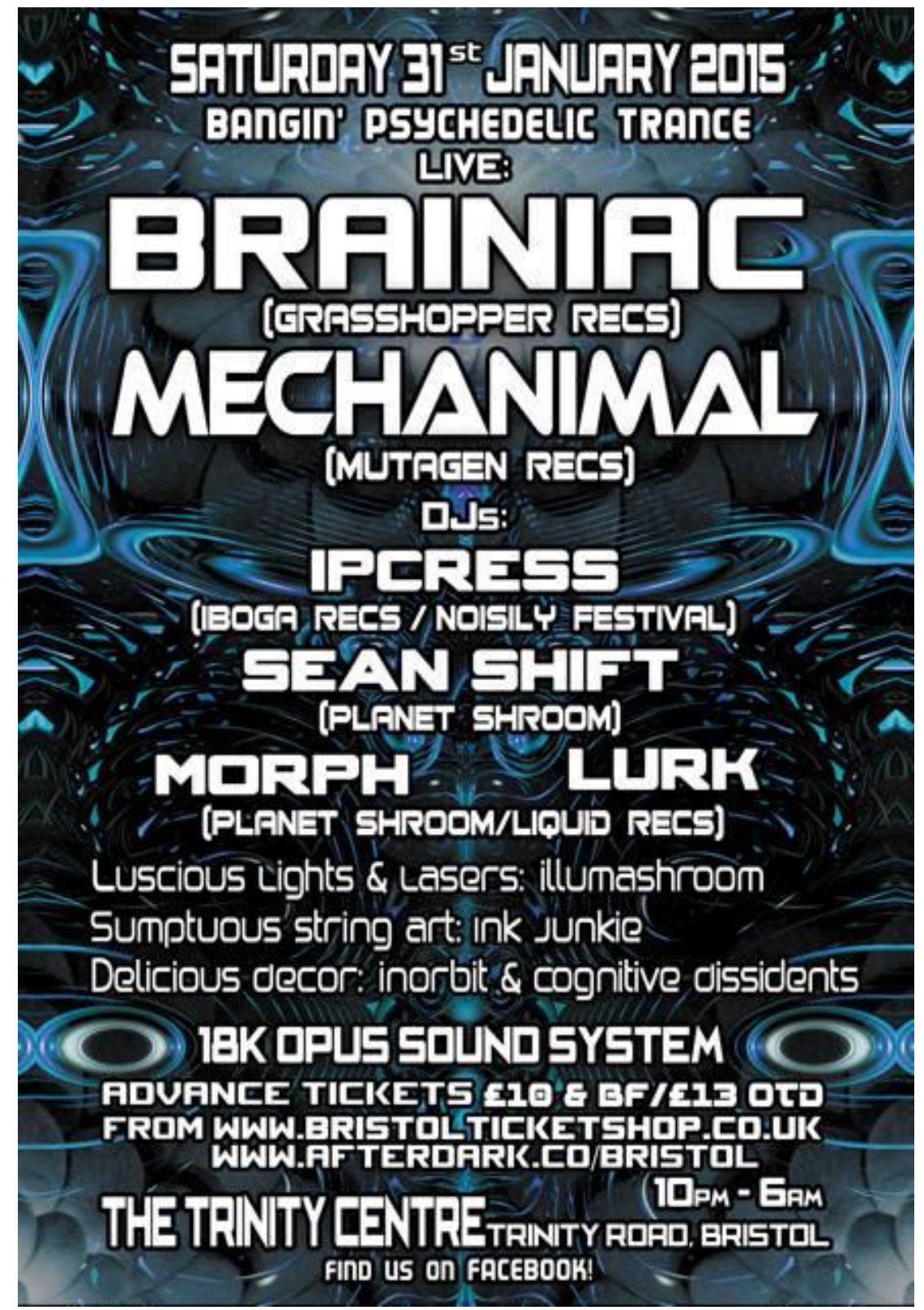

FIGURE 6. The Flyer for Planet Shroom, February 2015. 
Residence and affiliation are also crucial to the ways in which events are conceived and advertised. These appear prominently on promotional material, usually next to the name of the performer, as seen in Figure 6 . This serves to advertise the nature of the event and the aesthetic values of the promoters. Artists carry these associations with them to club nights and festivals across the world, representing the group to new audiences in different locations. This 'exchange' of tribe members strengthens the global psytrance network and creates social links which are vital to the maintenance of the international scene.

\section{Conclusion}

Although this paper has looked at only a handful of crews in one particular urban UDM scene, several observations can be made which may have wider applicability. First, crews have a pronounced core-periphery structure. Most consist of one or two central members who take responsibility for booking the venue and artists, with a wider network of friends and helpers who get involved in other ways. Much of the latter is physical work: providing and moving equipment, escorting artists to the venue, taking money on the door, etc. However, these participants are still involved at an aesthetic level. They do this work because they enjoy a particular kind of music and want to see it represented in their city. Although they do not make direct decisions about line-ups, equipment, or decorations, they nonetheless shape the live music ecosystem of which they are a part.

Second, it is evident that the motivations for UDM promotion today are not financial. Most events barely break even and only a handful make any income for the promoters. It is tempting to analyse the situation in terms of Bourdieu's (1979) 'cultural capital' or Thornton's (1995) 'subcultural capital': that is, to suggest that events display crewmembers' taste and cultural knowledge, and that by engaging in promotional activity they are rewarded with symbolic capital, allowing them to mobilise resources within the scene. This reading is supported by D'Andrea's (2007) analysis of DJ promoters in the early Goa scene and by the 'label nights' detailed earlier, which are a clear display of aesthetic prowess and pulling power within a UDM scene. However, these models do not take into account the internal diversity and aesthetic conflict within large music scenes, nor do they account for the risky nature of deploying cultural resources (Charles 2019). In addition, it is not apparent what exchange value this symbolic capital has for promoters, except to access the resources needed to put on further events. For the most part, it appears that UDM promotion is its own reward.

The explicit use of the term 'tribe' by psytrance crews may bring to mind Maffesoli's (1996) tribus and the subsequent literature on "neotribes" (Bennett 1999). These authors emphasise fluidity and the ease with which participants move between identities and aesthetics. Indeed, audiences move easily between events and musical styles; performers, too, have shifting allegiances with different groups and projects. However, as demonstrated here, promoters often show sustained commitment to their chosen aesthetic and to the maintenance of stable relationships between crewmembers, performers, regular attendees, and venues over long periods of time. This work is vital in facilitating further forms of musical participation. I suggest that a better model is provided by Finnegan's (2007) "pathways" which she describes as "a series of known and regular routes which people chose - or were led into - and which they both kept open and extended through their actions" (305). Crew membership is itself a pathway in urban musical life, and, through their efforts and contributions to local event cultures, crews create further pathways along which other participants may tread. 
Among these promotion-dependent pathways, residence is the most striking for its consistency. By offering regular work to DJs, promoters create structure out of what would otherwise be a disparate and haphazard series of musical encounters. Residence is also one of the few sources of local musical work in otherwise translocal music scenes. Where paid, it allows musicians to make their craft financially sustainable. However, it is not necessarily a stepping-stone to an international career or professional musicianship. Indeed, the local nature of residence means that it can be sustained alongside other types of work quite easily. Further research is needed on these crew-performer relationships in the context of contemporary music careers, especially among amateur and semi-professional performers.

Moving forward, it is likely that UDM crews in the UK will continue to struggle with the closure of independent venues and the rising cost of living, both of which affect the viability of putting on inner-city events for underground audiences. Making independent music sustainable will be a key challenge for scene participants, venue owners, and local authorities in coming years. Recognising the work that promoters do in maintaining music ecosystems will be vital to this work and to the continuing health of independent music in today's cities.

\section{Endnotes}

(1) Here, EDM is used in the traditional sense, referring to electronic dance music in general rather than the specific genre 'EDM' which has emerged more recently in the USA.

\section{References}

\section{Bibliography}

Becker, H. 1982. Art Worlds. London: University of California Press.

Bennett, A. -

1999. Subcultures or Neo-tribes? Re-thinking the Relationship Between Youth,

Style and Musical Taste. Sociology 33(3): 599-617.

2004. Consolidating the Music Scenes Perspective. Poetics, 32(3-4): 223-234.

Bourdieu, P. 1979. Distinction: A Social Critique of the Judgement of Taste.

Translated by Richard Nice 1987. Cambridge MA: Harvard University Press.

Brewster, B. and Broughton, F. 2007. Last Night a DJ Saved My Life. London: Headline.

Burton, E., and Berry, A. 2011. The Trinity Centre: Culture \& Change in Urban Bristol. Bristol: Trinity.

Butler, M. -

2006. Unlocking the Groove: Rhythm, Meter, and Musical Design in Electronic Dance Music. Bloomington, IN: Indiana University Press.

2014. Playing With Something That Runs: Technology, Improvisation, and

Composition in DJ and Laptop Performance. New York: Oxford University Press.

Charles, C. 2019. Psyculture in Bristol: Careers, Projects, and Strategies in Digital Music-Making. Ph.D. University of Bristol.

D'Andrea, A. 2007. Global Nomads: Techno and New Age as Transnational Countercultures in Ibiza and Goa. Oxford: Routledge.

Farrugia, R. 2012. Beyond the Dance Floor: Female DJs, Technology and Electronic Dance Music Culture. Bristol: Intellect. 
Fikentscher, K. 2000. "You Better Work!" Underground Dance Music in New York City. Middletown: Wesleyan University Press.

Finnegan, R. 2007. The Hidden Musicians: Music-Making in an English Town. Middletown: Wesleyan University Press.

Fogarty Woehrel, M. 2019. On Popular Dance Aesthetics: Why Backup Dancers Matter to Hip Hop Dance Histories. Performance Matters 5(1): 116-131.

Henning, M. and Hyder, R. 2015. Locating the 'Bristol Sound': Archiving Music as Everyday Life. In S. Cohen et al. Eds. Sites of Popular Music Heritage: Memories, Histories, Places. London: Routledge.

Henriques, J., 2010. Sonic Bodies: Reggae Sound Systems, Performance Techniques, and Ways of Knowing. London: Continuum.

Lindop, R. 2010. Re-Evaluating Musical Genre in UK Psytrance. In G. St John Ed. The Local Scenes and Global Culture of Psytrance. London: Routledge: 114130.

Madrid, A. 2008. Nor-tec Rifa! Electronic Dance Music from Tijuana to the World. New York: Oxford University Press.

Maffesoli, M. 1996. The Time of the Tribes: The Decline of Individualism in Mass Society. London: Sage.

O'Grady, A. 2015. Dancing Outdoors: DiY Ethics and Democratised Practices of Well-being on the UK Alternative Festival Circuit. DanceCult 7(1): 76-96.

Petiau, A. 2015. Free Parties and Teknivals: Gift-Exchange and Participation on the Margins of the Market and the State. Translated by Luis-Manuel Garcia. DanceCult 7(1): 116-128.

Reitsamer, R. 2011. The DIY Careers of Techno and Drum ' $\mathrm{n}$ ' Bass DJs in Vienna. Dancecult 3(1): 28-43.

Reynolds, S. 2013. Energy Flash: A Journey Through Rave Music and Dance Culture. London: Faber and Faber.

Rosca, M. 2014. Illegal Raves: Social media messages bring in a new generation of partygoers. The Guardian, [online] 16 April. Available at: < https://www.theguardian.com/music/2014/apr/16/illegal-raves-return-withsocial-media-messages $>$ [Accessed 29 September 2019]

Ruane, D. 2015. Harm Reduction or Psychedelic Support? Caring for DrugRelated Crises at Transformational Festivals. Dancecult 7(1): 55-75.

Saldanha, A., 2007. Psychedelic White: Goa Trance and the Viscosity of Race. London: University of Minnesota Press.

St. John, G. 2010. Psytrance: An Introduction. In G. St John Ed. The Local Scenes and Global Culture of Psytrance. London: Routledge: 1-17.

2011. DJ Goa Gil: Kalifornian Exile, Dark Yogi and Dreaded Anomaly. Dancecult 3(1): 97-128.

2012. Global Tribe: Technology, Spirituality and Psytrance. Sheffield: Equinox.

Straw, W. 1991. Systems of Articulation, Logics of Change: Communities and Scenes in Popular Music. Cultural Studies, 5(3):368-388.

Thornton, S. 1995. Club Cultures: Music, Media and Subcultural Capital. Oxford: Polity.

Vernon, J. 2018. Hip Hop, Hegel, and the Art of Emancipation: Let's Get Free. [ebook] New York: Palgrave Macmillan.

Vitos, B. 2009. The Inverted Sublimity of the Dark Psytrance Dancefloor. Dancecult 1(1): 137-141.

Webb, P. 2004. Interrogating the Production of Sound and Place: The Bristol Phenomenon from Lunatic Fringe to Worldwide Massive. In S. Whiteley et al. 
Eds. Music, Space and Place: Popular Music and Cultural Identity. Aldershot: Ashgate: 66-85.

Webster, E., 2011. Promoting Live Music in the UK: A Behind-the-Scenes

Ethnography. Ph. D. University of Glasgow. [Online] Available at:

<http://theses.gla.ac.uk/2955/> [Accessed 30 September 2016]

\section{Interviews}

Fractal Forest. 2018. Interviewed by Author, 20 January.

Krosis. 2017. Interviewed by Author, Bristol, 15 June.

Krosis. 2019. Interviewed by Author, Facebook, 29 September.

Lurk. 2015. Interviewed by Author, Bristol, 14 April.

Tetrasound. 2016. Interviewed by Author. Bristol, 24 February. 